\title{
Valores ciudadanos en la construcción de la marca país. Un análisis ecuatoriano
}

\section{Citizen values in the country brand construction. An Ecuadorian analysis}

INFORMACIÓN DEL ARTÍCULO

Fecha de recepción: 16 de Noviembre de 2018.

Fecha de aceptación: 4 de Diciembre de 2019.

1 Magíster en Escrituras Creativas, Universidad Nacional de Colombia. Docente e Investigadora de la Universidad Espíritu Santo-Ecuador. E-mail:sgpoveda@uees.edu.ec

Código ORCID:

https://orcid.org/0000-0003-4699-4533

$\overline{2}$ Licenciada en Relaciones Públicas y Eventos, Universidad Espíritu Santo. Investigadora de la Universidad Espíritu Santo-Ecuador.

E-mail: pau_gomez_behr@hotmail.com Código ORCID:

https://orcid.org/0000-0001-8417-1883

CITACIÓN: Poveda Benites, S. G., \& Gómez Behr, P. A. (2019). Valores ciudadanos en la construcción de la marca país. Un análisis ecuatoriano. PODIUM, (36), 73-88.

https://doi.org/10.31095/podium.2019.36.5

\section{ENLACE DOI:}

http://dx.doi.org/10.31095/podium.201 9.36 .5

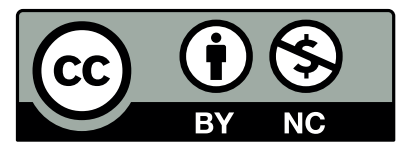

Sylvia Gisella Poveda Benites ${ }^{1}$, Paola Andrea Gómez Behr ${ }^{2}$

Resumen

En el branding de países es imprescindible resaltar los valores intangibles que representan a los ciudadanos, pero la marca país Ecuador Ama La Vida se enfocó en los aspectos materiales, naturales y geográficos, lo cual genera una imagen nacional fragmentada. Este estudio tiene por objeto identificar cómo una marca país puede ser consistente, eficiente y perdurable, a través de una revisión de teorías con respecto a la correcta construcción de marcas de lugares y un estudio sobre identidad ecuatoriana. Se realizó un benchmarking con otras campañas regionales de éxito que fue complementado con entrevistas a profesionales de las áreas de marketing, psicología organizacional y comunicación corporativa. Se concluyó que la marca país de Ecuador necesitaba incluir, dentro de su concepto clave, valores humanos-intangibles que permitan a sus ciudadanos desarrollar el sentido de pertenencia para transformarse en voceros naturales.

\section{Palabras Clave:}

Relaciones exteriores, impacto de la comunicación, estudio de mercado, investigación social, marketing, psicología social.

Clasificación JEL: M3, G3, F5.

\begin{abstract}
In the countries branding it is essential to highlight the intangible values that represent citizens, but the Ecuadorian country brand Ama La Vida focused on the material, natural and geographical aspects, which generates a fragmented national image. This study aims to identify how a country brand can be consistent, efficient and enduring, through a review of theories regarding the correct placemarks construction and a research about Ecuadorian identity. A benchmarking was carried out with other successful regional campaigns that was complemented by interviews with professionals in the areas of marketing, organizational psychology and corporate communication. It was concluded that the Ecuadorian country brand needed to include, within its key concept, human-intangible values that allow its citizens to develop the sense of belonging to become natural spokespersons..
\end{abstract}

\section{Keywords:}

External relationships, communication impact, market research, social research, marketing, social psichology.

JEL Classification: M3, G3, F5.

\section{3}

PODIUM No. 36, Diciembre 2019, pp. 73-88

(C) Universidad Espíritu Santo - UEES

ISSN: 1390-5473 e-ISSN: 2588-0969 


\section{Introducción}

Desde el año 2001, Ecuador inició un proceso de reinvención de imagen a través del lema "La vida en Estado Puro". Nueve años después surgió una nueva marca país, bajo la big idea "Ecuador ama la vida". Desde noviembre de 2013, el Ministerio de Comercio Exterior efectuó un proceso de reestructuración de la marca, a fin de promover los productos nacionales con capacidad de exportación; mejorando el posicionamiento de Ecuador a nivel internacional (Ministerio de Comercio Exterior, 2015). La actual marca país "Ecuador ama la vida", está enfocada en resaltar aspectos materiales, recursos naturales, y atributos geográficos representativos del territorio nacional.

Como problema se identificó que, dentro del paquete vendedor expuesto en la campaña, desde su lanzamiento en el año 2010 hasta finales de 2015, no se incluye el componente humano ni los valores intangibles que representan a los ciudadanos; factor que es resaltado como imprescindible por múltiples expertos y especialistas internacionales en lo referente a la construcción de branding de países alrededor del mundo. Por ello se planteó como hipótesis que la falta de difusión de los valores inmateriales ciudadanos incide en un concepto / mensaje fragmentado de la marca país Ecuador Ama la Vida. No obstante, la campaña ha tenido reconocimientos en los últimos cinco años, promocionando a Ecuador como un destino turístico de alto nivel. Por ejemplo, en la gala de los World Travel Awards 2014, premiación que resalta la excelencia turística y la hospitalidad, se hizo acreedor a 14 galardones entre ellos: Cuenca, Mejor Destino de Aventura 2014; Ecuador, por segundo año consecutivo, Destino Líder Verde de Suramérica; Quito, por segundo año consecutivo, Destino Líder de Suramérica y el Ministerio de Turismo de Ecuador, Mejor Oficina Turística del 2014 (Ministerio de Turismo Ecuador, 2014).

Con respecto a los índices del turismo nacional, en un comunicado emitido por la ministra Sandra Naranjo se comprobó que el número de visitantes extranjeros incrementó en el año 2013, de enero a julio en un 14\%; y desde el 2005 las inversiones en el sector se habían duplicado. Adicionalmente en 2014, el turismo en Ecuador generó directamente 127,500 puestos de trabajo $(1.7 \%$ del empleo total) y en una proyección al año 2025 se espera que estas plazas laborales aumenten a 165,000 (World Travel \& Tourism Council, 2015).

A pesar de la buena racha de reputación turística que ha venido experimentando Ecuador en los últimos años, expertos internacionales en marketing de países, encienden una luz de alerta, resaltando el hecho de que para que una estrategia de marca país funcione a largo plazo, es necesario que sea perdurable en el tiempo, que no cambie con los gobiernos de turno y sea coherente con aquello que representan sus ciudadanos; para conseguir solidez y estabilidad de marca e imagen, los nacionales de un país deben poder representar a su nación dentro del territorio $\mathrm{o}$ en el exterior pues todo miembro del grupo patrio es un vocero natural de la marca constituida como país 
(Marketing Activo, 2011). Precisamente este es el caso de los países que según el Country Brand Report (Future Brand, 2015), se postularon como las mejores marca país de Latinoamérica. En esta ocasión Brasil, Argentina y México se ubicaron en los primeros lugares seguidos por Chile, Perú, Costa Rica, Panamá, Cuba, Puerto Rico y Uruguay (América Economía, 2015).

Una marca a nivel país no se puede plasmar desde la perspectiva de una sola persona, sino a través de un proceso que contenga mayor participación. La construcción de una marca debe ser abierta, en donde participen si es posible, todos los miembros del país (Marketing Activo, 2011). Consecuentemente, el objetivo general de este estudio es identificar las características que permiten que una campaña de branding de país sea consistente, eficiente y duradera en el tiempo a través de la comunicación de los valores intangibles de sus ciudadanos. A su vez, como objetivos específicos se plantean el reconocer aquellas falencias de contenido en la campaña Ecuador Ama la Vida, analizar las teorías de expertos internacionales en lo que respecta a branding de lugares, y comparar la estrategia local con las demás campañas exitosas de la región.

\section{Revisión de literatura}

\section{El impacto de la identidad colectiva en las marcas}

En la Teoría de la Identidad Social (TIS), la identidad se conoce como aquel sentimiento que surge cuando un individuo se pregunta ¿quién soy? y experimenta una percepción en sí mismo, conectada con un sentido de pertenencia colectivo (Iglesias Sahagún, 2009). Además, la identidad comprende un autoanálisis por medio del cual las personas pueden descubrir sus capacidades y potencialidades. Sin embargo, como los individuos no están solos, ese autoconocimiento incluye también el reconocerse parte y componente de un grupo (Mercado Maldonado y Hernández Oliva, 2010).

Del mismo modo, la identidad es el vínculo que permite que un individuo se relacione con su grupo, para lo cual son necesarios tres requisitos clave: percepción de pertenencia, ser consciente de que el ser miembro le asigna un calificativo positivo o negativo y sentir un afecto derivado de ser parte de ese colectivo, tomando en cuenta aquellos atributos que consiguen que los individuos se sientan parte de una categorización determinada, rasgos que pueden definir con mayor facilidad las cualidades como la personalidad, las conductas sociales o las características físicas-étnicas. Complementariamente, la Teoría de la Identidad Social (TIS), establece que sin importar cuan compleja sea la imagen que tiene un individuo de sí mismo, algunos de los aspectos que componen ese concepto son aportaciones del entorno con el que se desenvuelve (Scandroglio, López Martínez, y San José Sebastián, 2008).

\section{La necesidad de la construcción de una marca pais}

Durante el Primer Congreso 
Iberoamericano DirCom 2015, se hizo referencia, como uno de los mayores problemas y retos de la actualidad en el mundo de la comunicación, a la infoxicación; entendida como un exceso de información que consumen los seres humanos a diario. La abundancia de contenido es la culpable de que cada vez los datos pierdan más impacto y recordación en nuestro cerebro. Como resultado, al tener que competir cada vez con más mensaje y estímulos publicitarios, las marcas y las organizaciones tienen que idearse nuevas estrategias que les permitan sobresalir y apoderarse de la atención de sus públicos (UDLA, 2015).

Por otro lado, la actualidad del mundo de la comunicación desmitifica la restricción aquella que sugiere que la publicidad, el marketing, las relaciones públicas y demás herramientas de la comunicación están diseñadas única y exclusivamente para las marcas y las organizaciones comerciales. "Los colectivos como instituciones públicas, administraciones territoriales $y$ organizaciones no gubernamentales, tienen las mismas necesidades de comunicación estratégica, integración de equipos humanos, mejoramiento de la eficacia, gestión de credibilidad, construcción de reputación e imagen pública, optimización de los resultados y beneficios sociales y generación de vínculos con los públicos” (Costa, 2015).

En México, por ejemplo, la imagen que se proyecta como país es lo que va a despertar $o$ no el interés de los inversionistas que se encuentran en el exterior; a final de cuentas es eso lo que contribuye e impulsa a un país determinado a lograr su identificación (IMEFI TV, 2014). Así, Costa (2015) explica que con el fin de construir una reputación, los países y las ciudades, cumpliendo el perfil de colectivos, se empoderan a través de la comunicación territorial o el branding de lugares, construyendo comunidades con el producto que los grupos tienen en común: su lengua, cultura, historia y sobre todo con los sentimientos que los identifican como unidad y a su vez, la estructura la siembran usualmente en las instituciones públicas, en las marcas líderes, los representantes políticos y con las celebridades más destacadas.

La marca país y sus poderes de transformación

Brujó (2014) confirma que en la actualidad las naciones son competidoras $\mathrm{y}$ buscan atraer hacia sus territorios turismo, inversión y comercio; aspecto que se facilita cuando existe una marca país con excelente reputación. En ese ámbito, a nivel de Latinoamérica y del mundo entero, existen grandes ejemplos a seguir. Naciones líderes que, a través de una reinvención inteligente de su marca territorial, han logrado superar expectativas y actualmente se encuentran encaminadas hacia un productivo porvenir turístico y económico, que funciona cuando se sienten parte y se identifican con el concepto y la estrategia de comunicación, incluye un trabajo en conjunto con gremios, universidades, personajes, líderes de opinión, periodistas, empresa privada y gobierno (Imagen de Chile, 
2014).

La idea del proyecto inclusivo es formar voceros o portadores de interés, en cada espacio y rama posible logrando trascender a lugares, personas $\mathrm{y}$ actividades, inclusive las marcas propias de un país pueden sumarse a la iniciativa con el fin de potencializar e introducir aún más esa identidad compartida como en el caso de Colombia, país en el que empresas como Avianca, Kokorico, Grupo AVAL y BBVA impulsaron inicialmente la promoción del mensaje (Echeverri, Rosker, y Restrepo, 2010).

Consecuentemente, en El Salvador, los mentalizadores de la campaña "El lado positivo del mundo", descubrieron que sus ciudadanos habían olvidado quiénes eran y han pasado mucho tiempo pendientes de ver quiénes son los demás y admirando atributos ajenos en vez de enfocarse en los propios. Por eso, la meta de la estrategia fue el recordar el origen y hacerlo propio (Colectivo País, 2014). A través de las investigaciones de las costumbres y los valores de sus ciudadanos, descubrieron finalmente los adjetivos que representan a los salvadoreños y sobre los cuales formularon la idea de campaña; tomando en cuenta que los productos se subdivididen en tangibles e intangibles (Aires y Nicolau, 2010).

En El Salvador hallaron satisfactoriamente como propiedades significativas que su gente es trabajadora, ingeniosa y siempre optimista, la idea se construyó iniciando con una proyección de puertas hacia fuera, no con un perfil maquillado solo para el exterior; de tal forma que el mensaje no oculta una realidad sino que motiva a los ciudadanos a demostrar lo que son y lo que sienten, en relación a sí mismos y hacia su país, haciendo énfasis en el positivismo, de allí el slogan de marca país, El Salvador+, el lado positivo del mundo (Colectivo País, 2014).

\section{Requisitos para construir una marca país ganadora}

En referencia al branding local, los propietarios de una marca nacional son sus ciudadanos, y si estos no logran transmitir los conceptos que la representan, la imagen no se reconoce como consistente, por ello es imprescindible que se lleve a cabo un reconocimiento profundo, con la finalidad de que los ciudadanos vivan y convivan con los valores expresados en el mensaje nacional, dando paso a una identificación con símbolos y a la generación de un sentido de pertenencia grupal (Marketing Activo, 2011). El hecho de que la marca Ecuador no refleje valores personales, dificulta el proceso de potencialización de portavoces espontáneos, por el contrario, sí puede identificarse fácilmente con valores intangibles que lo representen como la alegría, la responsabilidad, la pasión, la religiosidad, entre otros; una vez encontrados esos emblemas diferenciales e identificativos, se procede a difundir la marca localmente para su aprehensión y futura (también simultánea) difusión global. Allí se transmite marca, ideas y valores (Mercado Maldonado y Hernández Oliva, 2010). 
En la Tabla 1 se presentan los requisitos clave que Chaves (2012) recomienda para promulgar una marca país triunfante.

\section{CoMarketing, la comunicación de los ciudadanos}

El comarketing público no consiste en vender, ya que no hay vendedores ni clientes, ni consumidores, sino que implica compartir, cooperar, colaborar, codecidir, comunicar, cogestionar, complicidad, comunidad. Es decir, sumar diferencias y pluralidades para la ciudad y los ciudadanos. Como sustento, Marzano (2014), estableció

Tabla 1

Marca País: Requisitos y consecuencias

Característica / Requisito

Un país no se puede vender como producto

Todos los ámbitos y sectores de desarrollo del país deben verse incluídos

Los conceptos y valores que sustentan la marca deben ser más trascendentales que la innovación, originalidad o creatividad que se quieran lograr con una campaña

La imagen país es convencional y no es necesario inventarse temas confusos o rebuscados para generar un impacto

Una marca país debe tener institucionalidad Una marca país debe representar
emblematicidad

La marca país debe tener larga vigencia la mayor diferencia existente entre las marcas de productos y las marcas de país: En el caso de productos o servicios, se puede confiar en el alineamiento estratégico; ya que la marca es propiedad de una compañía, allí la empresa es responsable de los aciertos y desaciertos, por el contrario, con la marca de la nación, por más de que un gobierno se sienta dueño, no puede forzar a que sus portadores de interés lleven los valores de la marca puestos en sus hombros.

En lo que se conoce como la retórica del turismo, para un país la estrategia nace del
Consecuencias

La moda de transformar todo en un marca puede resultar en una construcción inestable y poco estratégica de imagen nacional. Esto solo genera declives anunciados, disrupciones anticipadas y conceptos poco aprehendidos en los portadores de interés de las naciones.

Podría generarse una discriminación de áreas, productos, patrimonios, culturas, economías, entre otros.

El intento de originalidad e innovación extrema puede distraer las funciones y el objetivo de la marca país.

El producir un mensaje complejo limita la claridad y la decodificación de las ideas por parte de los receptores.

La imagen de institucionalidad provee seguridad y respaldo.

El concepto de emblematicidad permitirá que sea asumible automáticamente por todos los nacionales, como signo de identidad del que nadie puede dudar.

Con la larga vigencia el concepto base no se transformará súbitamente, solamente se irá adaptando a los cambios naturales de las culturas.

Fuente: Cháves, 2012. 
encuentro; una colectividad se involucra por pertenencia. Por tal motivo, la construcción de una marca debe ser abierta para fomentar la participación de todos los actores y componentes del país, ya que los valores y atributos no se pueden plasmar desde la perspectiva de uno o pocos individuos, debiendo ser un proceso participativo e incluyente (Marketing Activo, 2011).

Acerca de la campaña "Ecuador Ama la Vida", en el primer intento de branding local, se creó una imagen natural, pero con la estrategia no se logró una recordación clara de la campaña. Luego, en 2013, después de haber lanzado "Ecuador Ama la Vida", el Ministerio de Comercio Exterior comenzó a liderar la iniciativa para revalorizar la imagen, enfocándola en los productos exportables (Marca país Ecuador: Ecuador ama la vida, 2010).

En un análisis de la percepción que tienen los adultos jóvenes de Suiza con respecto a la imagen que proyecta Ecuador, se llegó a concluir que es inapropiada y de corto alcance. La gran mayoría de los encuestados no identifican ni el logo ni el eslogan de campaña. De igual forma, asocian al país con destinos turísticos con diversidad de flora y fauna (Rosales, 2013).

\section{Así somos los ecuatorianos}

Ipsos (2014) llevó a cabo un estudio para conocer el perfil de los individuos ecuatorianos; comprendiendo sus valores, creencias, motivaciones y el impacto en su entorno. El compendio infográfico incluyó información estadística sobre la realidad de vida de los ecuatorianos y la satisfacción que sienten con su nación. Dentro del reporte se registran datos de perfil demográfico, características psicológicas, creencias, situación de vida y familia, responsabilidad social, política y gobierno, trabajo, ciencia y tecnología, principales objetivos e intereses, sociedad y visión de pertenencia. Asimismo, resalta atributos del ciudadano ecuatoriano como la alegría, la predilección por la vida familiar, la religiosidad, el patriotismo y el espíritu trabajador. En la Figura 1 se puede

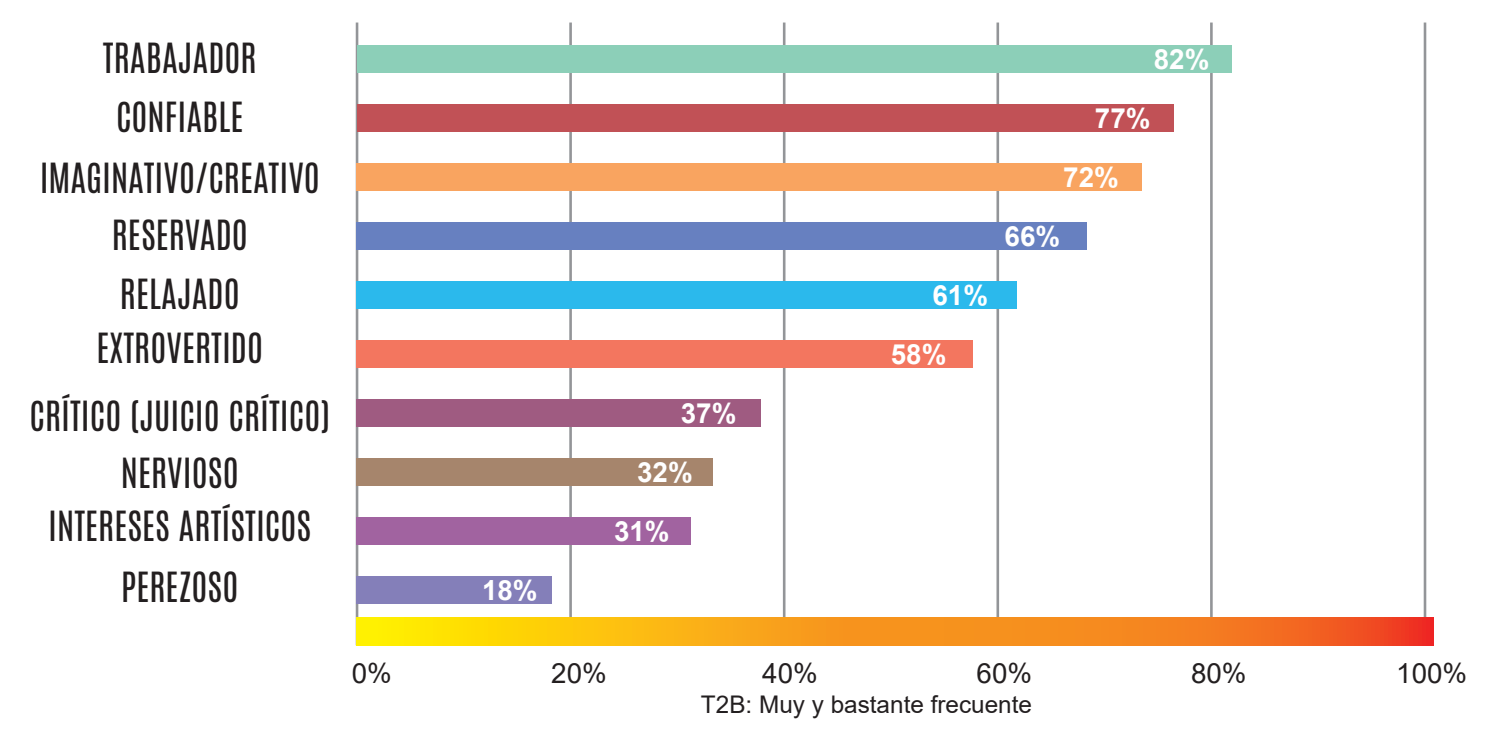

Figura 1. Calificativos con los que los ecuatorianos se reconocen a sí mismos. Fuente: Ipsos Consultor Ecuador 2014. 


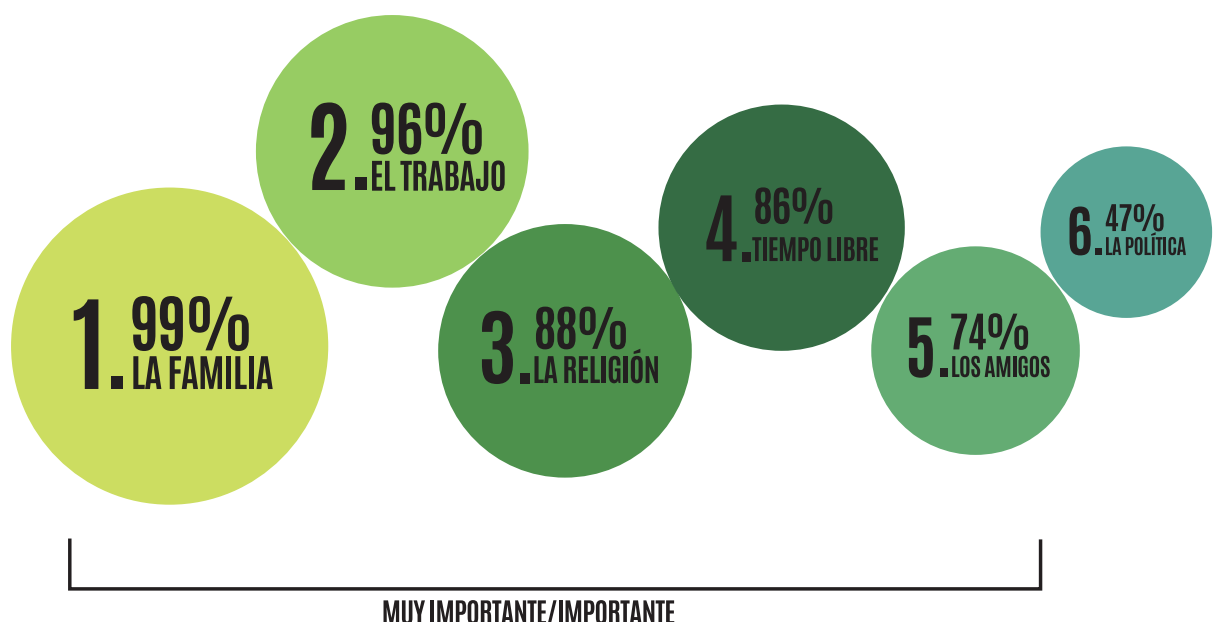

Figura 2. Los temas que los ecuatorianos consideran importantes.

Fuente: Ipsos Consultor Ecuador 2014.

observar que los ecuatorianos se consideran trabajadores ( $82 \%$ ) y confiables (77\%). Más del $50 \%$ se consideran precavidos y $97 \%$ se definen como creyentes en Dios.

Los tres aspectos que lideran la vida y las decisiones de los ecuatorianos: Familia, Trabajo y Religión (ver Figura 2). El 61\% de los ecuatorianos cuentan con trabajo y el $91 \%$ se sienten orgullosos de su nacionalidad.

\section{Metodología}

La metodología que se presenta en este trabajo es de carácter analítica y exploratoria. Se llevó a cabo un benchmarking con campañas exitosas de otros países de la región. Para la selección de casos se utilizaron como base dos categorizaciones con el listado de naciones ejecutoras de campañas de branding territorial en el continente: El ranking de Country Brand Report 2015/2016, y el listado de expositores del II Foro Internacional de Marca País llevado a cabo en Santiago de Chile en
2014. El año de realización de este estudio es el 2017, por lo cual se tomó en cuenta las dos últimas ediciones de las categorizaciones indicadas. Para complementar la investigación se hicieron entrevistas a expertos en las áreas del branding/marketing de países, la psicología organizacional y la comunicación corporativa. Entre los profesionales consultados se incluyeron a: Ana María Franco Medina, Coordinadora de Desarrollo Organizacional Transferunion S.A; Beatriz Manrique Miranda de Fernández, Directora 5entidos Terapia Organizacional; y el MBA Miguel Montalvo, Gerente General de TouchPoint Management, TPM.

\section{Resultados}

Con la globalización, los turistas pueden visitar naciones de todos los continentes sin tener que moverse de sus hogares. Las plataformas, el internet e incluso los mapas virtuales, permiten que un individuo conozca casi a detalle los lugares que en un futuro podría visitar. 
Esto, sin lugar a dudas, eleva la competencia turística a nivel global. Del mismo modo ocurre con los países y su imagen. Un territorio posicionado y reconocido a nivel internacional, inevitablemente atraerá la atención y elevará sus índices de visitantes; reforzando su industria turística $\mathrm{y}$ beneficiando, directa e indirectamente, su economía.

\section{Benchmarking}

En la Tabla 2 se presentan los resultados del benchmarking de doce estrategias de branding nacional de países de la región, destacándose que en diez de ellas incluyen la presentación de valores ciudadanos intangibles. Además, se involucran a personas, entre funcionarios públicos o personalidades del espectáculo, esto ratifica los criterios expuestos por los análisis de Marketing Activo (2011) en el que los propietarios de una marca nacional son sus ciudadanos. En el caso de Brasil, la creatividad y la alegría de las personas fue fundamental en los dos eventos deportivos (Olimpiadas y Mundial de Fútbol) que se realizaron durante esos años de la campaña "Brasil Sensacional" $\mathrm{y}$ que se destaca en otros eventos mundialmente conocidos como el Carnaval de Río de Janeiro. En las estrategias son importantes también las políticas de Estado, ya que dentro de los instrumentos de campaña se incluyen megaeventos o la aprobación de leyes como en el caso de Argentina que legalizó la unión de personas del mismo sexo. En El Salvador, con su campaña del "lado positivo" se incluyó el punto de vista del emprendimiento, lo que complementa lo expuesto por Aires y Nicolau (2010), sobre cómo las investigaciones de las costumbres y los valores de sus ciudadanos delinearon un perfil que los salvadoreños habían olvidado, apropiándose de forma auténtica de esta imagen que transmitieron a través de la campaña.

Tabla 2

Las mejores campañas de marca país de Latinoamérica.

\begin{tabular}{|c|c|c|c|c|c|}
\hline País & Slogan & Big Idea & Valores resaltados & Instrumentos & Vigencia \\
\hline Brasil & $\begin{array}{l}\text { Brasil } \\
\text { sensacional }\end{array}$ & $\begin{array}{l}\text { Potencia emergente y un } \\
\text { país de oportunidades. } \\
\text { Es un país colorido y } \\
\text { moderno. }\end{array}$ & $\begin{array}{l}\text { - Cualidades de su gente. } \\
\text { - Valores ciudadanos } \\
\text { intangibles como la } \\
\text { creatividad y la alegría. } \\
\text { - Historia } \\
\text { - Modernidad } \\
\text { - Aventura } \\
\text { - Gastronomía } \\
\text { - Cultura } \\
\text { - Playas } \\
\text { - Selva Amazónica } \\
\text { - Negocios } \\
\text { - Ecoturismo } \\
\text { - Experiencia } \\
\text { - Colores }\end{array}$ & $\begin{array}{l}\text { - Rol de anfitrión } \\
\text { en la Copa } \\
\text { Mundial de Fútbol } \\
2014 . \\
\text { - Anfitrión Juegos } \\
\text { Olímpicos } 2016 .\end{array}$ & $\begin{array}{l}\text { Desde el } \\
\text { año } 2008 .\end{array}$ \\
\hline
\end{tabular}


Tabla 2.

Las mejores campañas de marca país de Latinoamérica.

\begin{tabular}{|c|c|c|c|c|c|}
\hline País & Slogan & Big Idea & Valores resaltados & Instrumentos & Vigencia \\
\hline Argentina & $\begin{array}{l}\text { Más de una } \\
\text { razón. }\end{array}$ & Argentina late con vos. & $\begin{array}{l}\text { - Valores ciudadanos } \\
\text { intangibles como el } \\
\text { dinamismo. } \\
\text { - Turismo } \\
\text { - Cultura } \\
\text { - Deportes } \\
\text { - Inversiones } \\
\text { - Exportaciones }\end{array}$ & $\begin{array}{l}\text { - Selección de } \\
\text { fútbol en Mundial } \\
\text { de Sudáfrica de } \\
2010 . \\
\text { - Legalización de } \\
\text { matrimonio entre } \\
\text { personas de un } \\
\text { mismo sexo. }\end{array}$ & $\begin{array}{l}\text { Desde el } \\
\text { año } 2004 .\end{array}$ \\
\hline $\begin{array}{l}\text { México } \\
\text { méxıco }\end{array}$ & $\begin{array}{l}\text { México } \\
\text { unido, } \\
\text { diverso y } \\
\text { más allá de } \\
\text { la } \\
\text { hospitalidad. }\end{array}$ & $\begin{array}{l}\text { México es un puente de } \\
\text { encuentro entre la } \\
\text { tradición ancestral y la } \\
\text { vanguardia moderna }\end{array}$ & $\begin{array}{l}\text { - Valores ciudadanos } \\
\text { intangibles como calidez, } \\
\text { hospitalidad y alegría } \\
\text { - Riqueza natural } \\
\text { - Riqueza cultural } \\
\text { - Personalidad } \\
\text { - Modernidad } \\
\text { - Orgullo por el gusto a } \\
\text { la vida } \\
\text { - Arquitectura y arte }\end{array}$ & $\begin{array}{l}\text { Atracción de } \\
\text {,inversiones y } \\
\text { exaltación de } \\
\text { aspectos } \\
\text { empresariales. }\end{array}$ & $\begin{array}{l}\text { Desde el } \\
\text { año } 2005 .\end{array}$ \\
\hline ex & $\begin{array}{l}\text { Chile } \\
\text { sorprende, } \\
\text { siempre. }\end{array}$ & $\begin{array}{l}\text { Los chilenos a donde } \\
\text { quiera que vayan } \\
\text { sorprenden. }\end{array}$ & $\begin{array}{l}\text { - Valores ciudadanos } \\
\text { intangibles como el } \\
\text { emprendimiento } \\
\text { - Exportaciones } \\
\text { - Turismo } \\
\text { - Inversiones }\end{array}$ & $\begin{array}{l}\text { - Presentación de } \\
\text { tecnología única en } \\
\text { la región, como el } \\
\text { observatorio de } \\
\text { Chile. }\end{array}$ & $\begin{array}{l}\text { Desde el } \\
\text { año } 2005 .\end{array}$ \\
\hline Perú & $\begin{array}{l}\text { Hay un Perú } \\
\text { para cada } \\
\text { quien }\end{array}$ & $\begin{array}{l}\text { El amor por el Perú ya } \\
\text { no es sinónimo de una } \\
\text { sola nacionalidad. }\end{array}$ & $\begin{array}{l}\text { - Turismo } \\
\text { - Exportaciones no } \\
\text { tradicionales } \\
\text { - Inversiones }\end{array}$ & $\begin{array}{l}\text { - Viralización en } \\
\text { redes sociales de } \\
\text { activaciones para } \\
\text { fiestas patrias } \\
\text { como la } \\
\text { Blanquirrocola } \\
\text { - Apoyo del sector } \\
\text { privado. }\end{array}$ & $\begin{array}{l}\text { Desde el } \\
\text { año } 2011 .\end{array}$ \\
\hline Colombia & $\begin{array}{l}\text { El riesgo es } \\
\text { que te } \\
\text { quieras } \\
\text { quedar. }\end{array}$ & $\begin{array}{l}\text { Colombia es pasión, al } \\
\text { igual que todos los } \\
\text { colombianos. }\end{array}$ & $\begin{array}{l}\text { - Riqueza humana } \\
\text { - Valores ciudadanos } \\
\text { intangibles como la } \\
\text { pasión y la alegría } \\
\text { - Patriotismo } \\
\text { - Turismo } \\
\text { - Inversiones } \\
\text { - Exportaciones }\end{array}$ & $\begin{array}{l}\text { Estrategia de } \\
\text { apalancamiento y } \\
\text { trabajo en conjunto } \\
\text { con: } \\
\text { - Gremios y } \\
\text { Universidades } \\
\text { - Personajes } \\
\text { - Líderes de } \\
\text { opinión } \\
\text { - Periodistas } \\
\text { - Empresa privada } \\
\text { - Gobierno }\end{array}$ & $\begin{array}{l}\text { Desde el } \\
\text { año } 2005 .\end{array}$ \\
\hline
\end{tabular}


Tabla 2.

Las mejores campañas de marca país de Latinoamérica.

\begin{tabular}{|c|c|c|c|c|c|}
\hline País & Slogan & Big Idea & Valores resaltados & Instrumentos & Vigencia \\
\hline $\begin{array}{l}\text { Costa Rica } \\
\text { Costatrica }\end{array}$ & $\begin{array}{l}\text { Sin } \\
\text { ingredientes } \\
\text { artificiales. }\end{array}$ & $\begin{array}{l}\text { Es uno de los países más } \\
\text { exóticos del mundo; } \\
\text { donde se puede vivir con } \\
\text { salud y bienestar. }\end{array}$ & $\begin{array}{l}\text { - Valores ciudadanos } \\
\text { intangibles como la } \\
\text { autenticidad, solidaridad, } \\
\text { orgullo, alegría y calidez } \\
\text { - Talento humano } \\
\text { - Paz } \\
\text { - Democracia } \\
\text { - Prosperidad } \\
\text { - Ecoturismo }\end{array}$ & $\begin{array}{l}\text { - Propuestas de } \\
\text { exportaciones. } \\
\text { - Atracción de } \\
\text { innovaciones. }\end{array}$ & $\begin{array}{l}\text { Desde el } \\
\text { año } 2009 .\end{array}$ \\
\hline Panamá & $\begin{array}{l}\text { No tiene } \\
\text { slogan. }\end{array}$ & $\begin{array}{l}\text { Panamá es un país donde } \\
\text { se encuentra una de las } \\
\text { más importantes } \\
\text { poblaciones y reservas } \\
\text { de mariposas del mundo. }\end{array}$ & $\begin{array}{l}\text { - Negocios } \\
\text { - Diversión }\end{array}$ & $\begin{array}{l}\text { La imagen del país } \\
\text { está en constante } \\
\text { proceso de } \\
\text { construcción }\end{array}$ & $\begin{array}{l}\text { Está en } \\
\text { constante } \\
\text { cambio de } \\
\text { imagen, } \\
\text { aspecto } \\
\text { que ha sido } \\
\text { criticado } \\
\text { por su falta } \\
\text { de } \\
\text { efectividad }\end{array}$ \\
\hline Cuba & $\begin{array}{l}\text { Cuba } \\
\text { auténtica }\end{array}$ & $\begin{array}{l}\text { Cuba es más que una } \\
\text { playa. }\end{array}$ & $\begin{array}{l}\text { - Valores ciudadanos } \\
\text { intangibles como la } \\
\text { hospitalidad y la alegría } \\
\text { - Naturaleza virgen } \\
\text { - Arquitectura } \\
\text { - Locaciones para } \\
\text { vacacionar }\end{array}$ & $\begin{array}{l}\text { - Producción de } \\
\text { videos } \\
\text { institucionales para } \\
\text { redes sociales. } \\
\text { - Relación con } \\
\text { productos } \\
\text { nacionales como el } \\
\text { sello de las cajas } \\
\text { de habanos y el } \\
\text { diseño del Ron } \\
\text { Bacardi. }\end{array}$ & $\begin{array}{l}\text { Desde el } \\
\text { año } 2013 .\end{array}$ \\
\hline Puerto Rico & $\begin{array}{l}\text { Puerto Rico, } \\
\text { la isla } \\
\text { estrella }\end{array}$ & $\begin{array}{l}\text { Puerto Rico ha } \\
\text { producido más talento de } \\
\text { clase mundial por milla } \\
\text { cuadrada que cualquier } \\
\text { otro país en el mundo. }\end{array}$ & $\begin{array}{l}\text { - Valores ciudadanos } \\
\text { intangibles relacionados } \\
\text { al emprendimiento y a } \\
\text { su alta capacidad } \\
\text { profesional. } \\
\text { - Riqueza cultural } \\
\text { - Economía } \\
\text { - Destino turístico }\end{array}$ & $\begin{array}{l}\text {-Esfuerzo } \\
\text { multisectorial } \\
\text { apalancando el } \\
\text { mensaje entre las } \\
\text { empresas privadas } \\
\text { y gobierno. } \\
\text {-Apoyo en artistas } \\
\text { nacionales como } \\
\text { Marc Anthony, } \\
\text { Gilberto Santa } \\
\text { Rosa, Calle } 13 .\end{array}$ & $\begin{array}{l}\text { Desde el } \\
\text { año } 2013 \\
\text { iniciaron } \\
\text { la } \\
\text { construcci } \\
\text { ón de la } \\
\text { promoció } \\
\text { n de } \\
\text { marca. }\end{array}$ \\
\hline
\end{tabular}


Tabla 2

Las mejores campañas de marca país de Latinoamérica.

\begin{tabular}{|c|c|c|c|c|c|}
\hline País & Slogan & Big Idea & Valores resaltados & Instrumentos & Vigencia \\
\hline $\begin{array}{l}\text { El Salvador } \\
\text { gelpulater }\end{array}$ & $\begin{array}{l}\text { El lado } \\
\text { positivo del } \\
\text { mundo. }\end{array}$ & $\begin{array}{l}\text { Los salvadoreños son } \\
\text { positivos, ingeniosos y } \\
\text { proactivos. }\end{array}$ & $\begin{array}{l}\text { - Valores ciudadanos } \\
\text { intangibles como el } \\
\text { positivismo, el espíritu } \\
\text { de emprendimiento y la } \\
\text { Proactividad. } \\
\text { - Se centra en su gente. }\end{array}$ & $\begin{array}{l}\text { A la campaña se } \\
\text { sumaron abogados, } \\
\text { economistas, } \\
\text { medios de } \\
\text { comunicación, } \\
\text { productores de } \\
\text { café y de azúcar, } \\
\text { marcas } \\
\text { exportadoras, entre } \\
\text { otros. }\end{array}$ & $\begin{array}{l}\text { Desde el } \\
\text { año } 2013 .\end{array}$ \\
\hline Uruguay & $\begin{array}{l}\text { Uruguay } \\
\text { Natural }\end{array}$ & $\begin{array}{l}\text { Uruguay no es } \\
\text { convencional, se } \\
\text { distingue. Uruguay es } \\
\text { calidad de vida. }\end{array}$ & $\begin{array}{l}\text { - Valores ciudadanos } \\
\text { intangibles como } \\
\text { independencia, disidencia, } \\
\text { inconformismo y las ganas } \\
\text { de experimentar. } \\
\text { - Resalta símbolos patrios. } \\
\text { - Industria agropecuaria } \\
\text { - Calidad de productos } \\
\text { - Cuidado del medio } \\
\text { ambiente. }\end{array}$ & $\begin{array}{l}\text { - Promoción de } \\
\text { productos } \\
\text { nacionales en el } \\
\text { exterior, sobre todo } \\
\text { el vino. }\end{array}$ & $\begin{array}{l}\text { Desde el } \\
\text { año } 2001 .\end{array}$ \\
\hline
\end{tabular}

Fuente: Future Brand, 2015; Imagen de Chile, 2014.

Tabla 3.

Campaña de marca país "Ecuador ama la vida"

\begin{tabular}{|c|c|c|c|c|c|}
\hline País & Slogan & Big Idea & Valores resaltados & Instrumentos & Vigencia \\
\hline $\begin{array}{l}\text { Ecuador } \\
\text { ecuador }\end{array}$ & $\begin{array}{l}\text { Ecuador ama } \\
\text { la vida. }\end{array}$ & $\begin{array}{l}\text { Ecuador potencia } \\
\text { turística. Lo mejor de } \\
\text { cuatro mundos }\end{array}$ & $\begin{array}{l}\text { - Productos exportables. } \\
\text { - Características } \\
\text { geográficas. } \\
\text { - Biodiversidad. }\end{array}$ & $\begin{array}{l}\text { - Ferias } \\
\text { internacionales } \\
\text { - Exportación de } \\
\text { productos } \\
\text { - Activaciones con } \\
\text { visibilidad mundial } \\
\text { como BTL de } \\
\text { letras en espacios } \\
\text { públicos y } \\
\text { exposición del } \\
\text { TVC en el Super } \\
\text { Bowl. }\end{array}$ & $\begin{array}{l}\text { Desde el } \\
\text { año } 2010 .\end{array}$ \\
\hline
\end{tabular}

Fuente: Cháves, 2012.

En la Tabla 3 se presenta la campaña marca país de Ecuador, realizada en el periodo 2010-2015.

\section{Entrevistas a expertos}

Motivación para un colectivo de

\section{nacionales}

La necesidad de motivación hacia los ciudadanos miembros de un colectivo, es uno de los temas en los que los entrevistados expertos coincidieron. Se priorizó la retroalimentación constante 
como la motivación más eficaz para promover el desarrollo de un equipo. También se consideró que la relación entre los líderes y los demás miembros del conjunto, debe transmitir expectativas, motivaciones, equilibrio y coherencia. Esto puede verificarse en las campañas de marcas país que tienen sinergia con las políticas a nivel de Estado que favorecen apertura al mundo, ya sea con la organización de eventos deportivos o la aprobación de leyes.

\section{Liderazgo para la motivación de} valores intangibles

Para proponer atributos intangibles primero se debe tener la declaración de valores creada en conjunto con el equipo, un objetivo claro de porqué y para qué. A la hora de gestionarlos debe primero hacérselo con el ejemplo como líder, y luego con políticas y prácticas establecidas que hagan que se respeten estos valores. De allí la importancia de definir el mensaje clave que se está pensando posicionar. En el caso de Puerto Rico aprovecharon la popularidad de sus cantantes de salsa emblemáticos para convertirlos en el valor humano intangible de estas campañas (Tabla 1).

Para complementar, los entrevistados también señalaron que la comunicación siempre va a ser una vía constructiva para cualquier situación organizacional. Si por este canal se logra una adecuada llegada hacia un equipo de colaboradores, se transmiten y consolidan valores que van a ser aceptados por los miembros de una organización. En el caso de marca país, la identidad colectiva bien aplicada podría generar reacciones positivas en los ciudadanos de una nación. Si se logra tansmitir un mensaje puntual, a través del colectivo identificado, este podría funcionar como una profecía autocumplida, tal como en el caso de Colombia y su campaña "El riesgo es que te quieras quedar". En este mensaje se juega con un mensaje positivo de la palabra riesgo, cambiando el valor por la hospitalidad y alegría de su gente.

\section{Identificación con los co-ciudadano}

Los entrevistados resaltaron lo que ha logrado el alcalde de Guayaquil con los habitantes, el sentido de orgullo, destacando tradiciones, rescatando sitios icónicos y creando hitos históricos que los representen. En cuanto a la identificación de valores grupales que se plasman en el colectivo y a su vez en cada individuo que lo conforma, es trascendental manejar una idea clara y definida; que tenga soporte en todas las acciones que se ejecuten. De esa forma existe la coherencia y la cohesión con las ideas o atributos que quieran promoverse. Esto ha funcionado además en países como Chile que destaca cualidades únicas como sus actividades en el Observatorio Astronómico.

\section{Factores que facilitan la identificación}

Todo aquello que los participantes compartan y tengan en común, hará que se sientan vinculados como unidad. Por el contrario, las causas más comunes que funcionan como obstáculos para la unificación son el rechazo, la 
discriminación, el chantaje y sobre todo el conflicto de intereses, prejuicios o valores.

\section{Lo que reconoce el ecuatoriano en $\mathrm{su}$} gente

Los expertos señalaron como valores representativos de los ecuatorianos. el respeto a la naturaleza, el altruismo, el éxito comunitario, el desarrollo sostenible, la sinceridad, honradez, credibilidad, unión familiar, solidaridad y el apoyo entre personas cercanas. Estas ideas concuerdan con el perfil del ecuatoriano de ser una persona creyente, familiar y trabajadora (Ipsos, 2014).

\section{Riesgo en la selección de los intangibles}

Con respecto a la selección del valor ciudadano que servirá de fundamento para la imagen nacional, una vez concebida la big idea, es necesario hacer un testeo inicial de campaña para comprobar que el valor o los valores que se elijan como bandera representativa del país, son efectivamente aquellos que van a lograr generar el lazo e identificación con los nacionales. Podría ser que los atributos seleccionados no representen al perfil mayoritario. En un país tan diverso como Ecuador, con varias costumbres, tradiciones y características por regiones, pareciera que los atributos geográficos son lo más especial de su cultura. En cuanto a las características de la campaña Ecuador Ama la Vida (ver Tabla 2), se indica que es lo mejor de cuatro mundos y se hace énfasis en su diversidad. En las campañas, las personas que aparecían en los comerciales y las vallas eran extranjeros que disfrutaban de los paisajes ecuatorianos.

\section{Conclusiones}

Luego de realizar el benchmarking se puede concluir que el punto común de las marcas que ocupan los primeros lugares es la inclusión de los valores intangibles ciudadanos como estrategias de sus marcas país, proyectando estas cualidades a través de megaeventos, personalidades reconocidas, profesiones diversas y un trabajo conjunto con los medios de comunicación, Estado y universidades. El peor error que puede cometerse al dibujar los planos de construcción de un país, es olvidarse de su propia gente e ignorar que la marca tiene que ser relevante para los ciudadanos del país. Es más importante hablar con el propio pueblo antes que hablar con los turistas; de allí se edifica el orgullo nacional. En el caso particular de los nacionales ecuatorianos, los valores que más destacan, según el reporte de Ipsos (2014) son: Familia, trabajo, alegría, religiosidad y orgullo nacional. Por consiguiente, dentro de estos valores debería testearse el más asumible por la población, para desarrollar y concebir en torno a ese atributo, el concepto de marca país Ecuador.

Unificando las teorías, la opinión de los expertos en materia y el análisis comparativo de estrategias en la región, la campaña Ecuador Ama la Vida, es funcional y ha traído consigo muy buenos resultados para el sector turístico 
nacional. Sin embargo, para alcanzar resultados óptimos y de manera prolongada, a la marca país actual le hace falta el componente humano; ese valor intangible que permita que sus habitantes se vean reflejados y se identifiquen con mayor claridad con la idea de nación. De esa manera podrán transformarse en speakers naturales, que fortalezcan $\mathrm{y}$ perennicen la imagen de Ecuador; facilitando la personalización y el sentido de apropiamiento de marca.

A principios de 2016, luego de más de cinco años de planificación y ejecución estratégica de la campaña de marca país Ecuador Ama la Vida, en la que se resaltaron netamente atributos geográficos, recursos naturales $\mathrm{y}$ biodiversidad, los gestores de la marca nacional comenzaron a difundir un video con una modificación de campaña en la que se incluyeron en breves rasgos valores ciudadanos de los ecuatorianos. La producción denominada "La belleza de Ecuador está en su gente", es el primer paso hacia la construcción de un branding nacional mucho más robusto y consistente.

\section{Referencias}

Aires, G., y Nicolau, K. C. (2010). Marketing turístico internacional. La Marca Brasil. Estudios y Perspectivas en Turismo, 19, 241-267.

América Economía. (9 de noviembre de 2015). Brasil, Argentina y México lideran ránking de marca país en Latinoamérica. Recuperado de: http://www.americaeconomia.com/econo mia-mercados/finanzas/brasil-argentinay-mexico-lideran-ranking-de-marca-paisen-latinoamerica
Brujó, G. (1 de diciembre de 2014). La importancia de una marca-país bien gestionada. Recuperado de: https://www.marketingdirecto.com/punto -de-vista/la-columna/la-importancia-de-u na-marca-pais-bien-gestionada-gonzalobrujo

Chaves, N. (2012). Marca país, vestimenta o disfraz. TEDx Buenos Aires 2012. Recuperado de https://www.youtube.com/watch?time_c ontinue $=12 \& v=w Y e L i 4 S I m H w \&$ feature $=$ emb title

Colectivo País. (2014). El Salvador, el lado positivo del mundo. Recuperado de: https://www.behance.net/ColectivoPais.

Costa, J. (2015). El paradigma DirCom. Barcelona, España: Joan Costa Institute.

Echeverri, L. M., Rosker, E., y Restrepo, M. L. (2010). Los orígenes de la marca país Colombia es pasión. Estudios $y$ Perspectivas en Turismo, 19(3), 409-421.

Future Brand. (2015). Country Brand Report América Latina 2015-2016. Recuperado de: https://www.codigo.pe/wp-content/uploa ds/2015/11/FutureBrand_CBR_America Latina 2015.pdf

Iglesias Sahagún, L. G. (2009). Una pesquisa genealógica de la idea-fuerza de “identidad". Aproximación psicosociológica. Revista Psicología y Sociedad, 9, 16-21.

Imagen de Chile. (2014). II Foro Internacional de Marca País - Santiago 2014. Panel 1: Experiencias de Gestión de Marca País. Recuperado de: https://www2.marcachile.cl/proyectos/iiforo-internacional-de-marca-pais-santiag o-2014/

IMEFI TV. (2014). ¿Qué es la Marca País? Tú y las Finanzas. Recuperado de: https://www.youtube.com/watch? $\mathrm{v}=7 \mathrm{gU}$ knp14gbw\&list=PL-ZByDpHxLQo3oIT zIPB2DNWkJc2oIV6a\&index $=91 \& \mathrm{t}=0 \mathrm{~s}$ 
Ipsos. (2014). Así somos los ecuatorianos. World Values Survey. Autopercepción sobre valores, tendencias y calidad de vida. Recuperado de:

https://edupasion.ec/pdf/As\%C3\%AD $\% 2$ 0somos $\% 201$ los $\% 20$ ecuatorianos. $\% 20$ Est udio $\% 20 \mathrm{de} \% 20$ autopercepci $\% \mathrm{C} 3 \% \mathrm{~B} 3 \mathrm{n}$ $\% 20$ sobre $\% 20$ valores, $\% 20$ tendencias $\% 2$ 0y\%20calidad $\% 20$ de $\% 20$ vida.pdf

Marca país Ecuador: Ecuador ama la vida. (2010). Recuperado de:

http://ecuadoramalavida.blogspot.com/

Marketing Activo. (17 de febrero de 2011). Marca país: la nueva imagen del Ecuador para el mundo, parte I. Recuperado de:

http://marketingactivo.com.ec/marca-pai s-la-nueva-imagen-del-ecuador-para-elmundo-parte-i/

Marzano, G. (20 de junio de 2014). Cómo construir la marca de un país. Recuperado de https://newmedia.ufm.edu/video/como-c onstruir-la-marca-de-un-pais/

Mercado Maldonado, A., y Hernández Oliva, A. V. (2010). El proceso de construcción de la identidad colectiva. Convergencia, 17(53), 229-251.

Ministerio de Comercio Exterior. (2015). Marca País Ecuador: Ecuador ama la vida.

Ministerio de Turismo de Ecuador. (9 de agosto de 2014). Ecuador gana 14 premios en los World Travel Awards, considerados los 'Óscar' del Turismo. Ministerio de Turismo. Recuperado de:

https://www.turismo.gob.ec/13937/

Rosales, K. A. (2013). Investigación y análisis de la percepción de la imagen del Ecuador como destino turístico en los adultos jóvenes de Suiza. (Tesis de pregrado). Universidad de Cuenca, Cuenca, Ecuador.

Scandroglio, B., López Martínez, J. S., y San José Sebastián, M. C. (2008). La Teoría de la Identidad Social: una síntesis crítica de sus fundamentos, evidencias y controversias. Psicothema, 20(1), 80-89.

UDLA. (2015). Primer Congreso Iberoamericano DirCom 2015. Recuperado de: https://www.udla.edu.ec/wp-content/uplo ads/2015/03/Entrevista-JC-Congreso-Dir Com-2.pdf

World Travel \& Tourism Council. (2015). 2015 Annual Research: Key Hightlights. Recuperado de http://www.wttc.org/

PODIUM No. 36, Diciembre 2019, pp. 73-88

(C) Universidad Espíritu Santo - UEES

ISSN: 1390-5473 e-ISSN: 2588-0969 